This article has been scanned by iThenticat No plagiarism detected

Volume 3, Issue 6, December 2021

p. $175-186$

\title{
EDUCATION AND ITS ROLE IN THE MORAL AND COGNITIVE CHANGE OF YOUNG PEOPLE
}

http://dx.doi.org/10.47832/2757-5403.6-3.13

\section{Maha Esam ABDULHAMED ${ }^{1}$}

\begin{abstract}
:
The educational institution today is one of the most important institutions that works to achieve and disseminate knowledge values among its members, and since the educational institution is at the same time a social institution, it reflects the goals, principles, values, behaviors and knowledge of that society to which it belongs through a set of concepts and values associated with each other to lead Its role is to immunize members of society in general and the youth group in particular against the fierce attack that young people are exposed to, threatening their Arab identity, social fabric and national affiliation to lead them to change the style and style of their culture and their knowledge and societal values.

What the world is witnessing today in terms of rapid events and changes represented by the moral and cognitive change that surrounded many aspects of the lives of young people, as a result of the great cultural openness and the intellectual invasion of various modern technological means whose impact has become vast on generations, especially the youth among them, as young people have become chanting phrases, concepts and behaviors that are not complete in our society. The matter went beyond defending these misconceptions, which necessitated the solidarity of all members of society, especially education and all its institutions, to restore the lost balance and defend our lofty values.

The Iraqi society was characterized by preserving the system of values, customs, knowledge and general principles until 2003 as it was a closed society and after that year and the rapid changes and transformations it was subjected to following its sudden and unprecedented contact with the outside world, in addition to the rapid deterioration in the economic and political conditions and the security chaos are all factors They

\footnotetext{
${ }^{1}$ Researcher, AL- Nahreen University, Iraq, maha.esam.1981@gmail.com, https://orcid.org/0000-0002-1621$\underline{6397}$
}

Copyright C Published by IJHER Journal, www.ijherjournal.com Rimar Academy, Fatih, Istanbul, 34093 Turkey

All rights reserved 
gathered to lead individuals in general and youth in particular to excessive use of modern technological means and an attempt to imitate and copy everything they saw without taking into account the values and knowledge of our society.

The study was prepared according to three sections. In the first section, we dealt with the subject of the study, its importance and objectives, with a statement of the most important concepts and terms contained therein.

Key words: Education, Value Change, Youth, Cognitive Change.

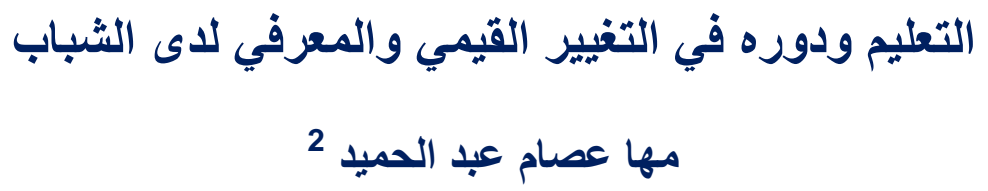

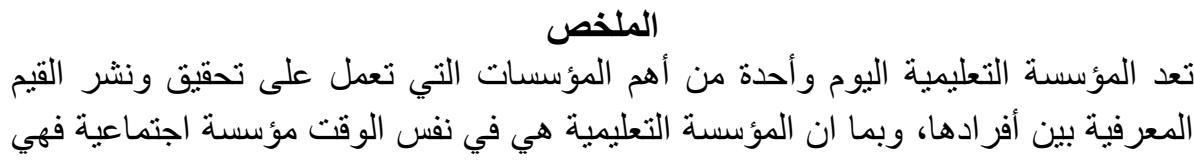

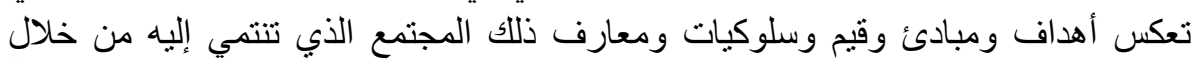

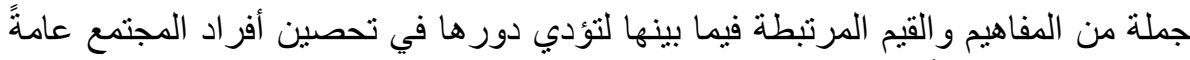

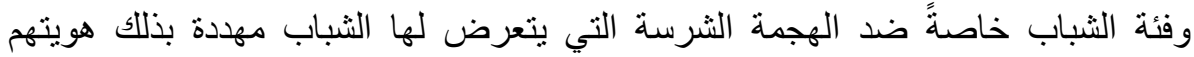

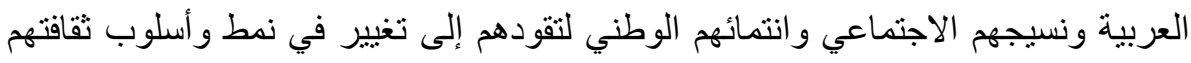
وقيمهم المعرفية و المجتمعية.

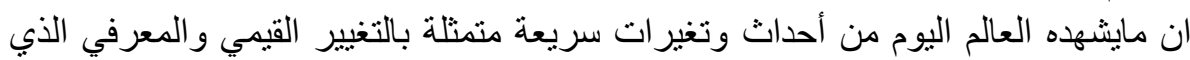

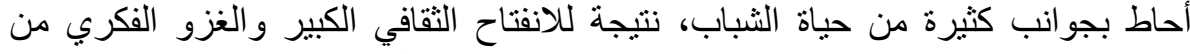

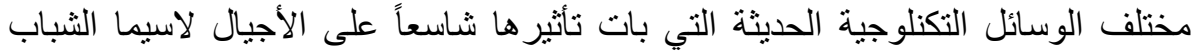

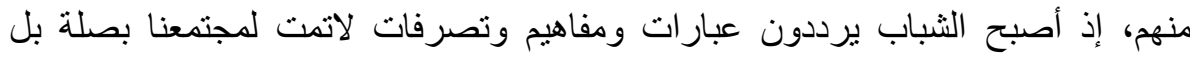

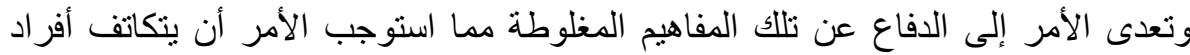

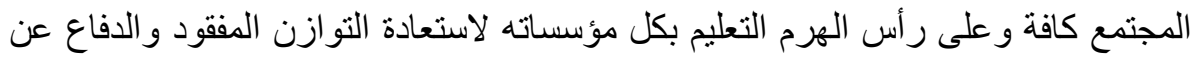

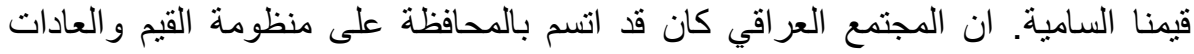

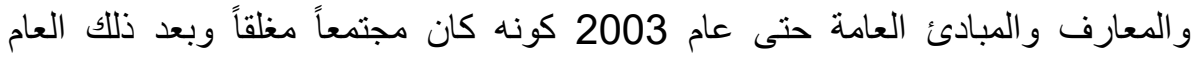
وماتعرض إليه من تغيرات وتحولات سريعة عقب أحتكاكه بالعالم الخارجي بصورة التانيا

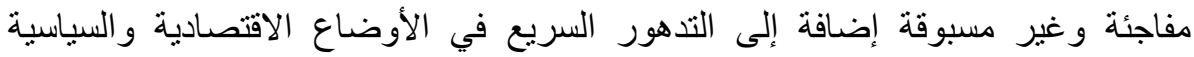

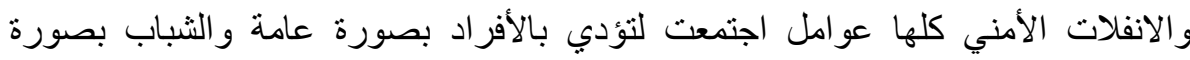

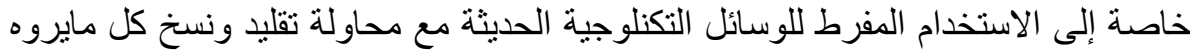

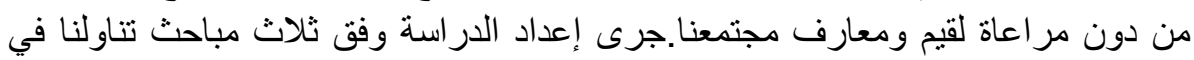

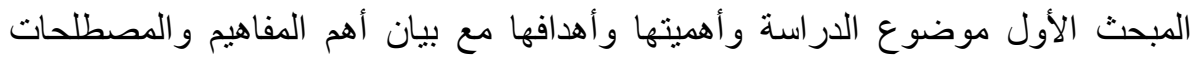

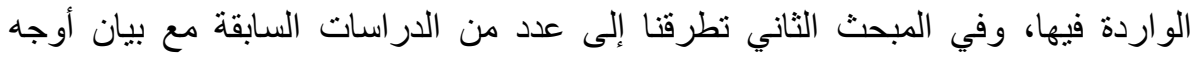

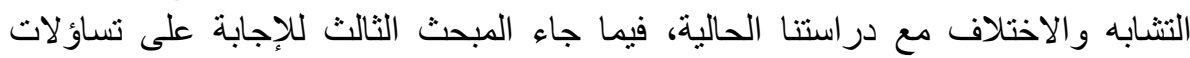




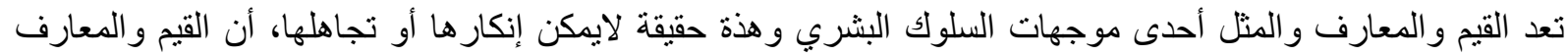

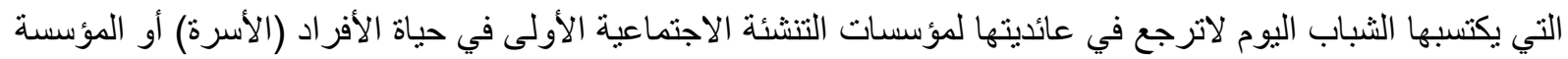

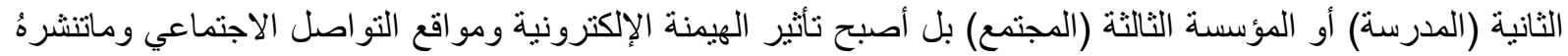

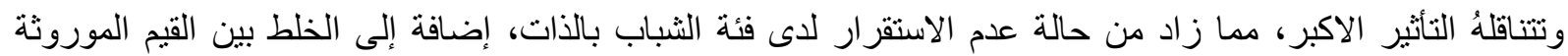

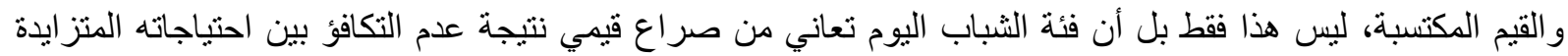

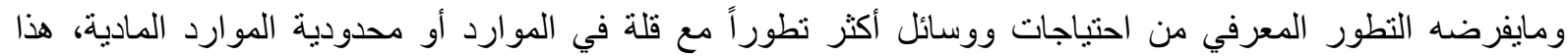

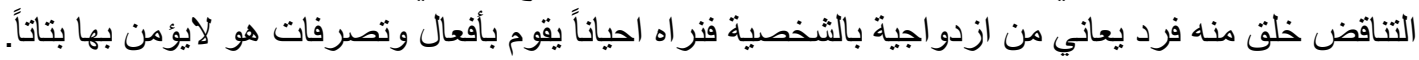

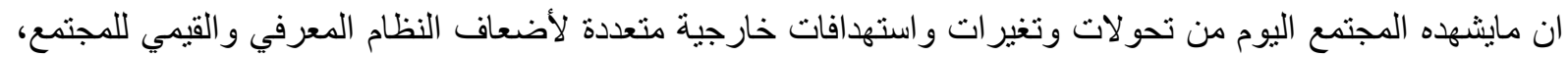

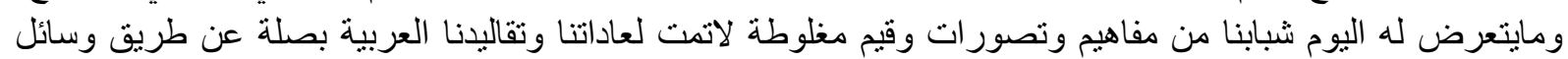

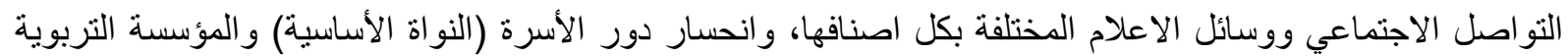

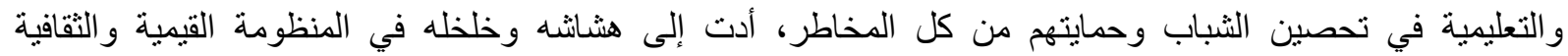

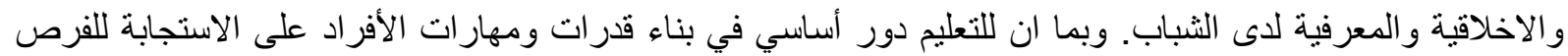

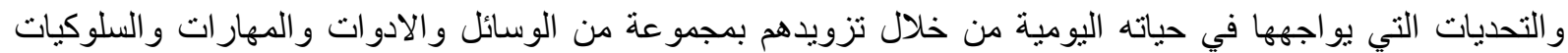

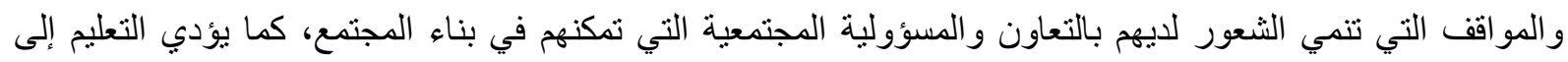

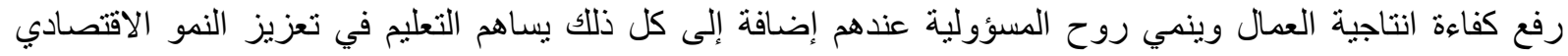

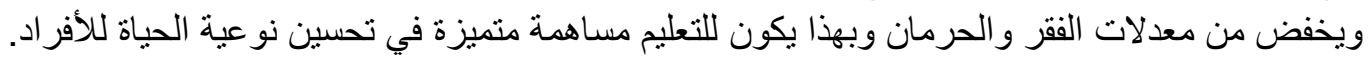

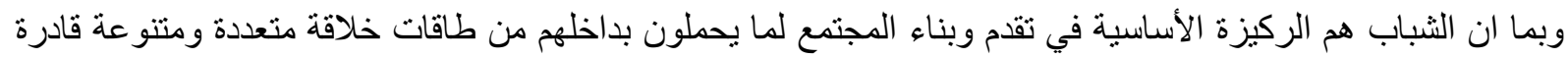

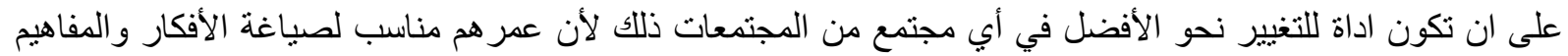

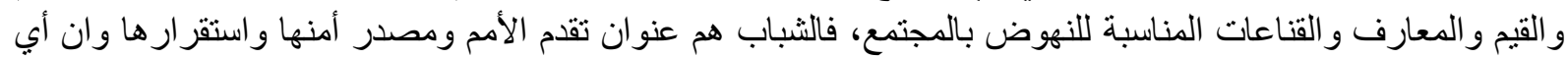

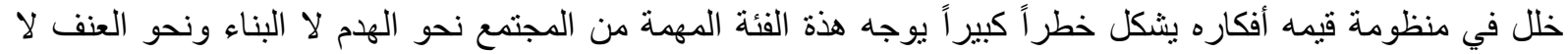
السلم و الأمن و الأمان.

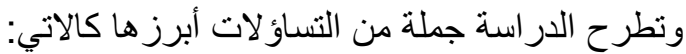

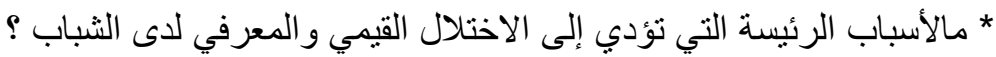

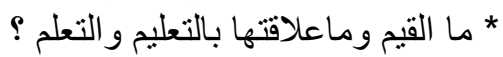

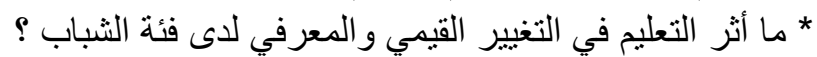
* هل لوسائل التو اصيل الاجتماعي تأثير في التغير القيمي و المعرفي للأفر اد بشكل عام وللثباب بشكل خاص ؟

أهمية الدراسة:

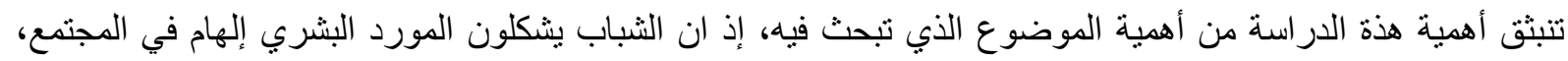

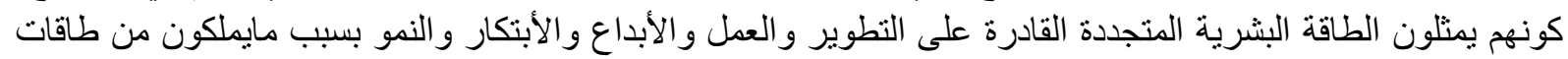
خلاقة و أفكار إبداعية نيرة. ذهبت هذة الدر اسة إلى تسليط الضوء ألى على التعليم ودوره في تنمية وضبط المنظومة القيمية و المعرفية لاى الثباب، وبيان

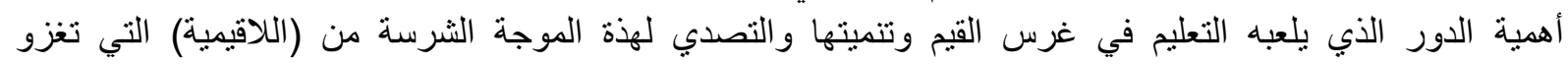

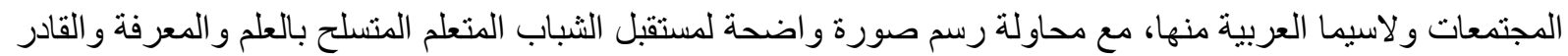

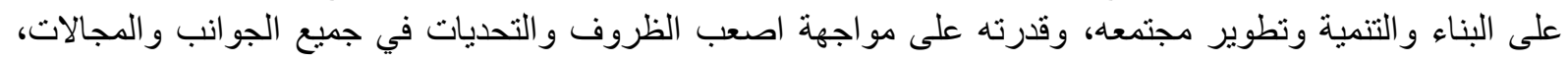

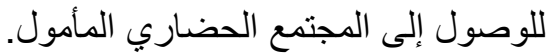

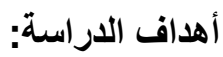

ترمي هذة الدر اسة إلى تحقيق الأهداف الأتية: * * بيان العلاقة بين التعليم وبين القيم المجتمعية وكيفية غرسها في نفوس الثنباب.

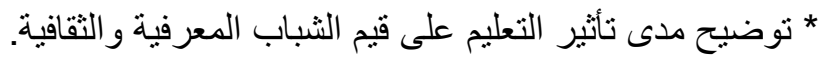




\section{EDUCATION AND ITS ROLE IN THE MORAL AND COGNITIVE CHANGE OF}

\section{YOUNG PEOPLE}

* بناء تصور معرفي عن مفهوم القيم وتوضيح أثر ها على الثباب.

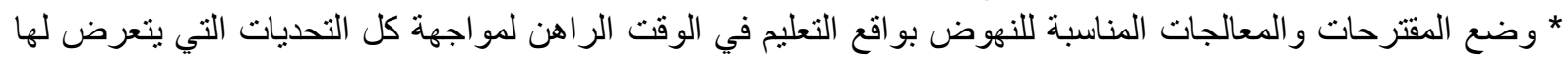

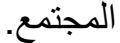
* إضافة مساهمة علمية جديدة في مجال التعليم و أثره في تنمية المنظومة القيمية للثباب.

$$
\text { المصطلحات والمفاهيم الواردة في الدراسة: }
$$

: 1

هو نثاط إنساني يحدث في كل زمان ومكان، يتمثل في توفير الثروط المادية والنفسية الملائمة التي تساعد وتحفز المتعلم

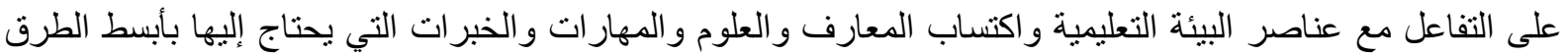

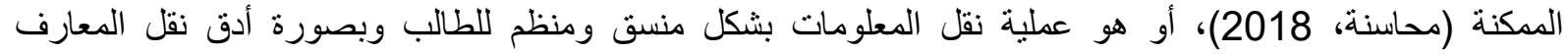
والخبرات و المهار ات التي يتم اكتسابها من فبل المتعلم بطرق مختلفة (احمد، 2018)

:Role - الدور 2

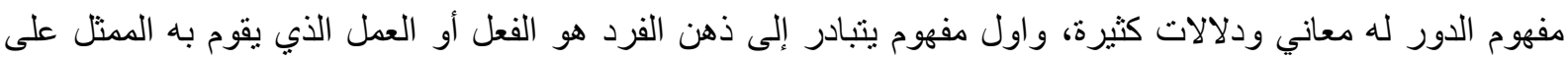

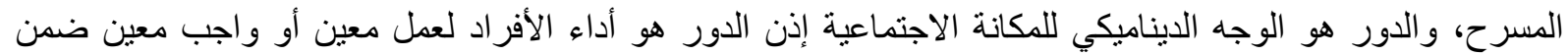

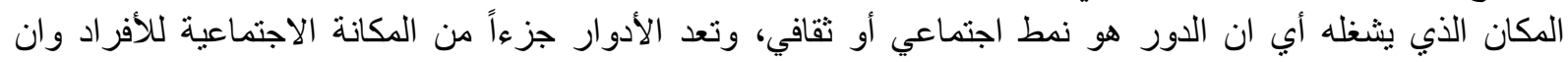

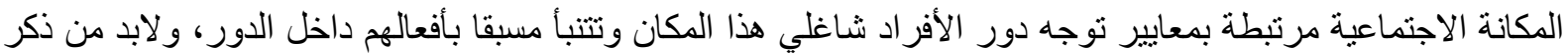

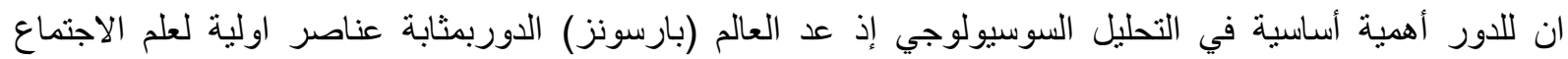

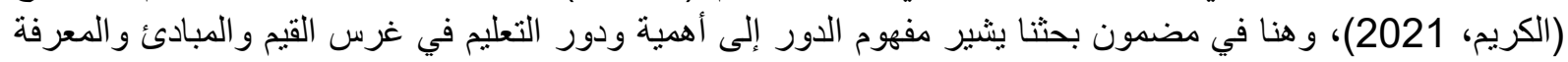
في نفوس الثباب.

\section{:Change - التَغيير 3}

هو عملية التحرك والانتقال من وضع إلى وضع أخر أكثر كفاءة وفاعلية، أو هو خطة بعيدة المدى لتحسين أداء الأفراد

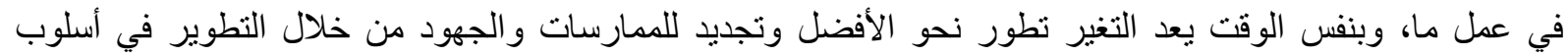

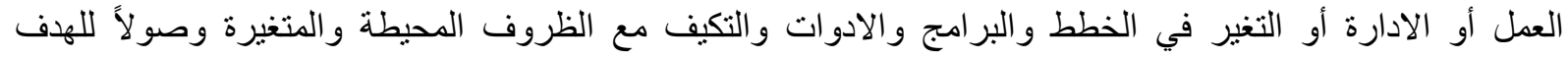

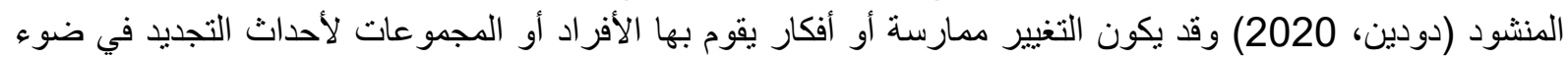

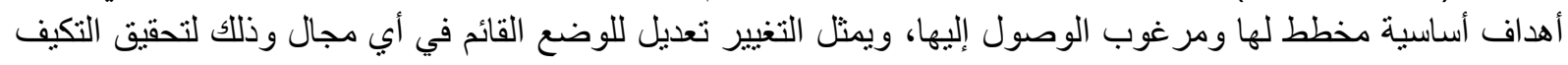

و التفاعل مع البيئة المحيطة بالفرد (المشاقبة، 2014)

: Value - 4

اختلف مفهوم القيم باختلاف الكتاب و الباحثين وباختلاف تناولهم للمفهوم وأن هنالك ثلاث عوامل أدت إلى الاختلاف

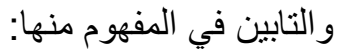
* تعدد العلوم و المناهج التي تناولت مفهوم القيم.

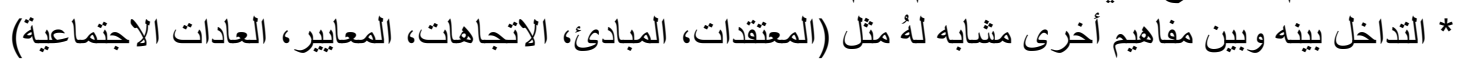
* تم تناوله لمدة من الزمن في إطار غير منهجي.

وقد وصفه أحد الباحثين بأنه " موضوع هلامي الملامح عالي التجريد يخضع لعوامل ذانية " (الدويش، 2012)

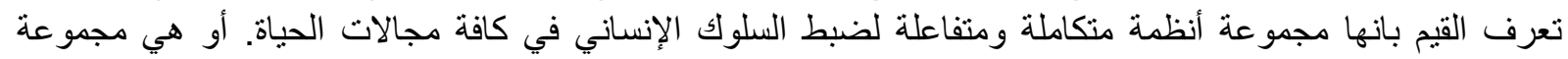

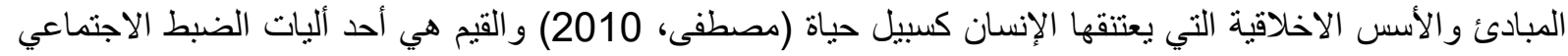

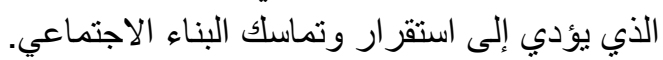

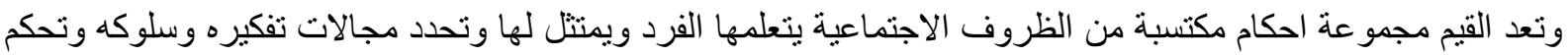

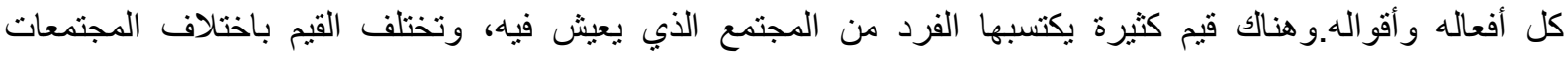

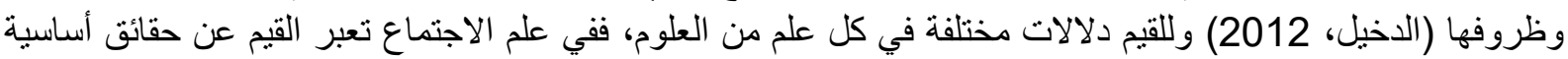

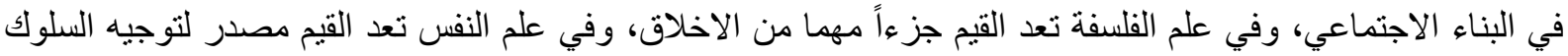


الإنساني و هي التي ترشده إلى الطريق الصحيح، إما في علم الاقتصاد فتعني مقدار ماتضيفه السلع والخدمات إلى الأشياء

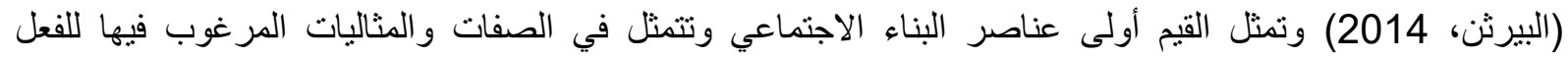

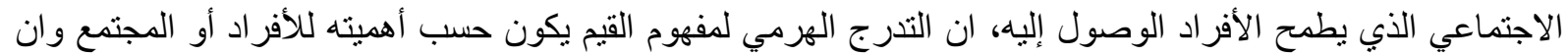

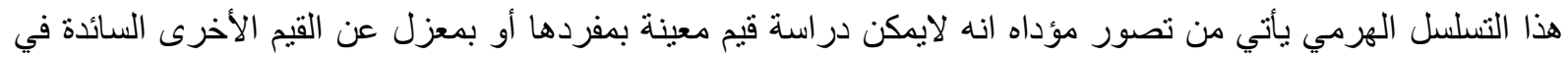

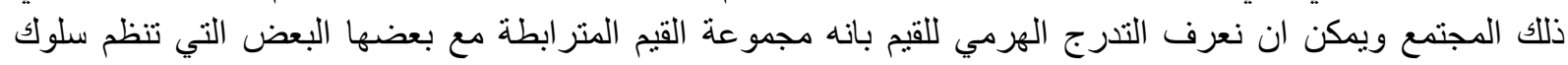
الأفر اد وتصر فاتهم وتكون مرتبة أو متسلسلة من القيم الأكثر أهمية إلى القيم الاقل أهمية (الكافي، 2003)

:Knowledge - المعرفة

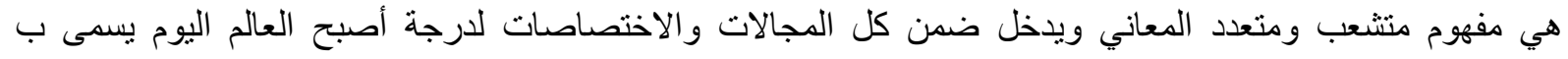

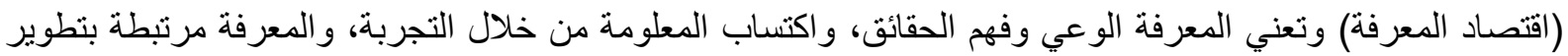

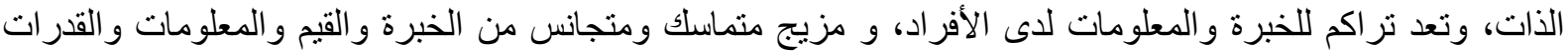

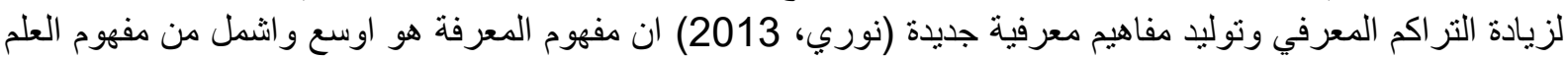

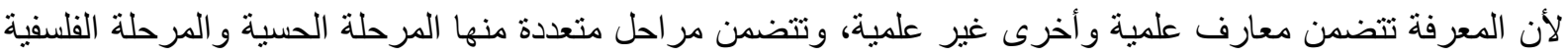

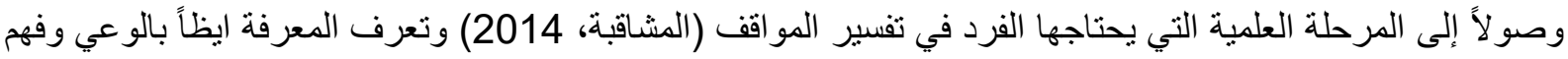

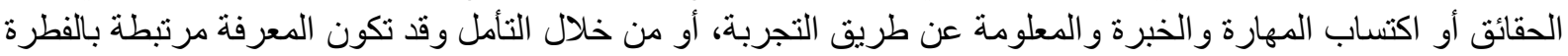
أو البديهية وتطوير الذات (البيرثن، 2014)

:Young - الثباب 6

حاول الكثير من الكتاب والباحثين وضع مفهوم محدد للشباب، لكن في الحقيقة نجد ان المفهوم متداخل في عدة حقول

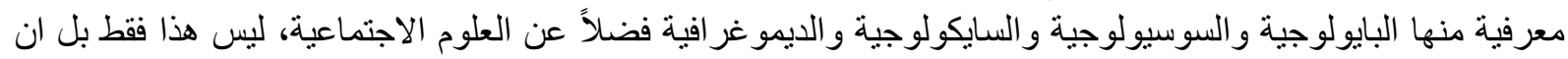

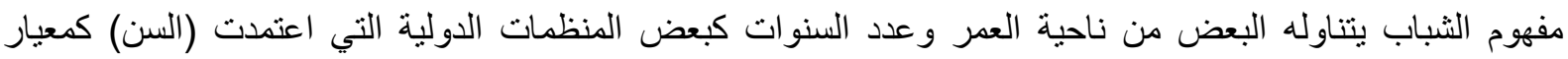

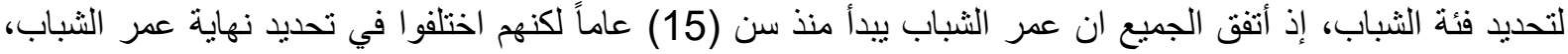

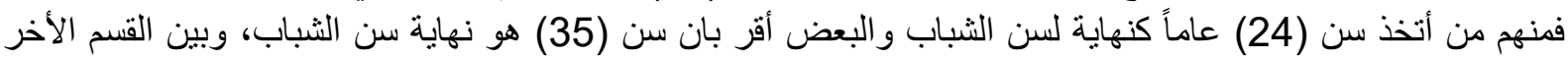

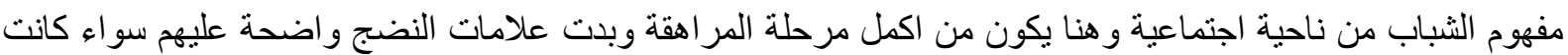

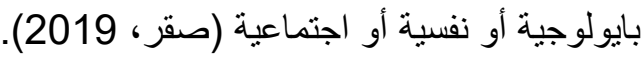

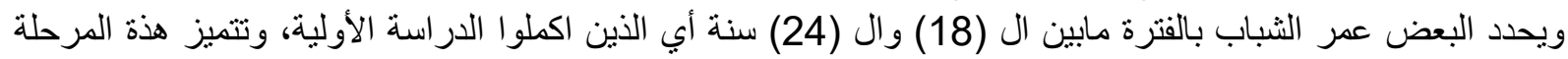

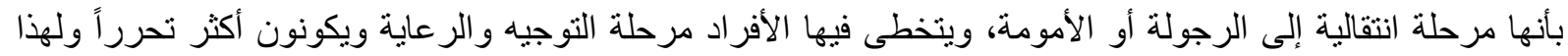

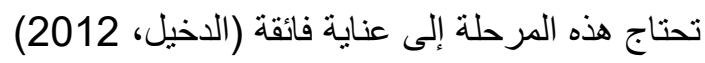

\section{المبحث الثاني \\ نماذج من الاراسات السابقة}

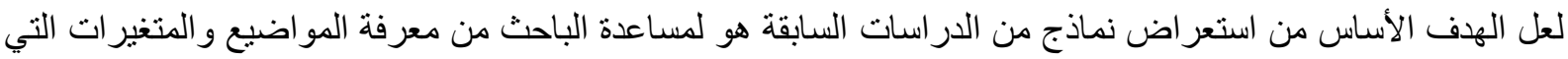

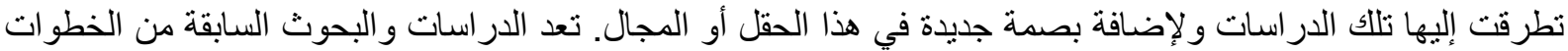

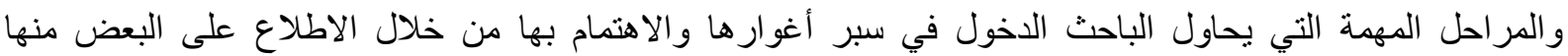

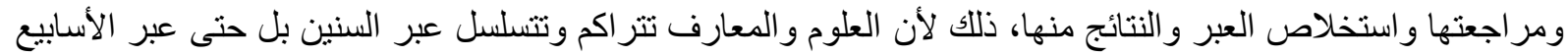

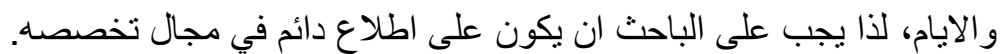

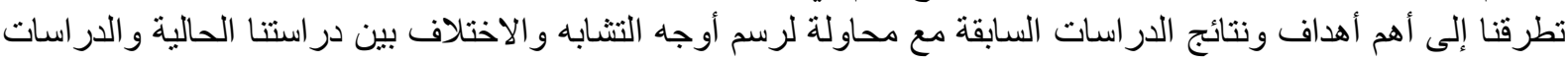
السابقة.

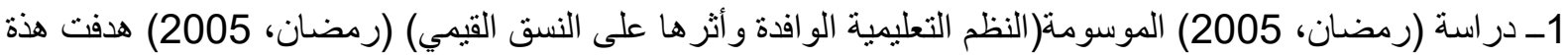

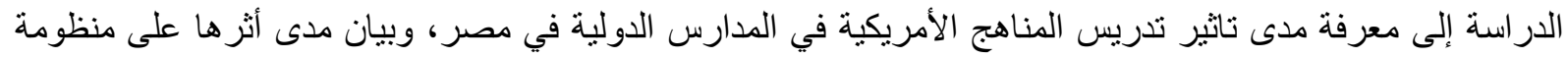


قيم الأفراد في مصر. استخدم الباحث المنهج الوصفي في درأسته لوصف طبيعة المناهج المتبعة في المدارس الدولية،

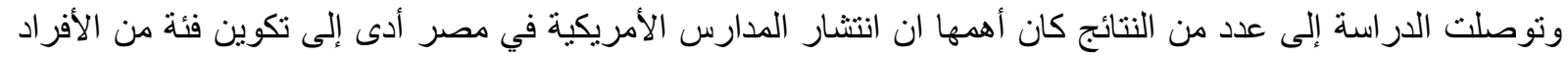

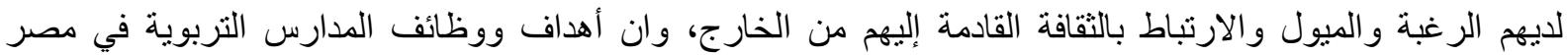

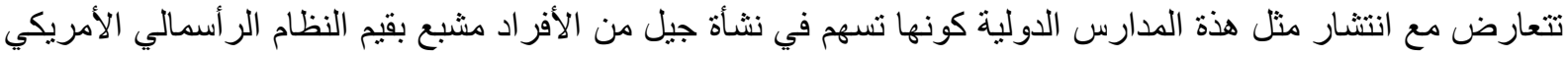

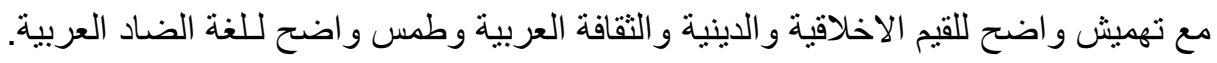

2 ـ دراسة (محمد، 2008) الموسومة (الإعلان التلفزوني وقيم المجتمع المسلم في إطار العولمة) (محمد ا.، 2008)

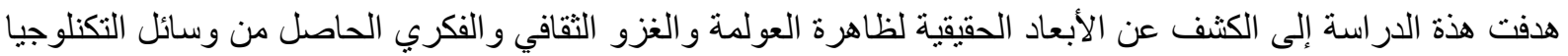

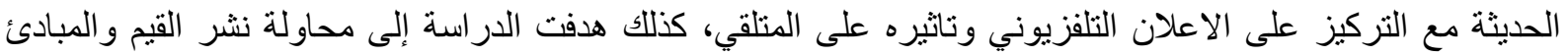
الاسلامية السامية بين الأفراد وكيفية تمكين المجتمع من الحفاظ عل هويته العربية ونسيجه الاجتماعي. استخدم الباحث

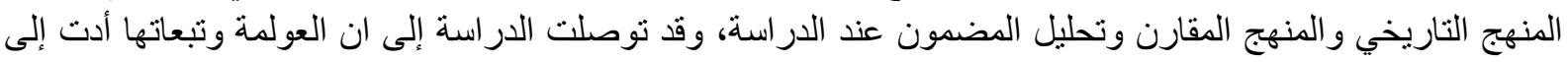

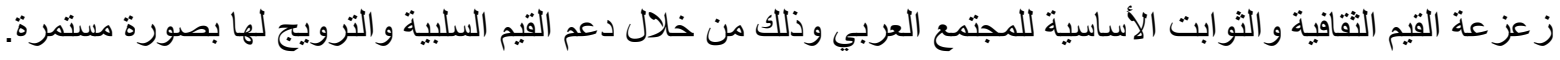
3 ـ دراسة (السلمي، 2019) الموسومة (مفهوم القيم وأهميتها في العملية التربوية ونطبيقاتها السلوكية من منظور

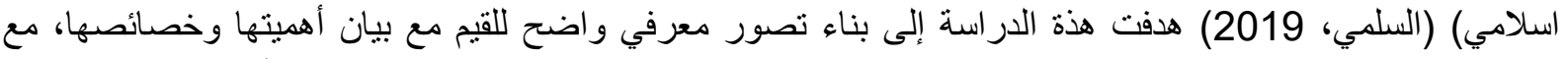

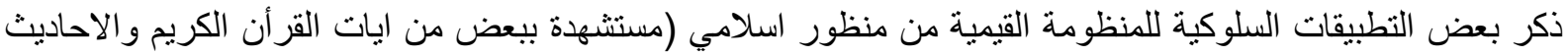

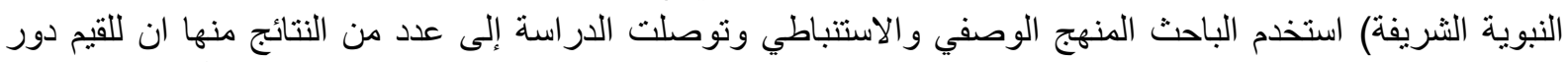

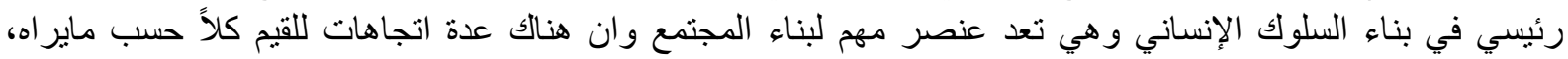

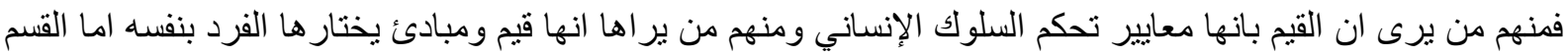
الثالث فيرى القيم بانها حاجات ودو افع شخصية للفرد.

أوجه التشابه بين دراستنا والدراسات السابقة هي:

اتفقت دراستنا الحالية مع الدراسات السابقة في بيان أهمية القيم في حياة الأفر اد و المجتمعات وان العولمة و التطور العلمي

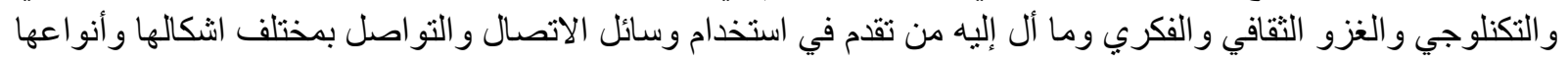

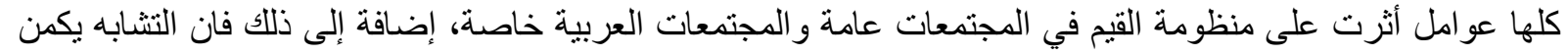

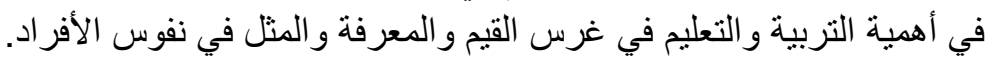

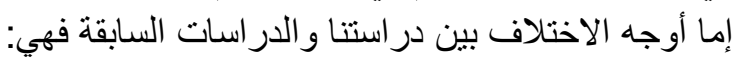

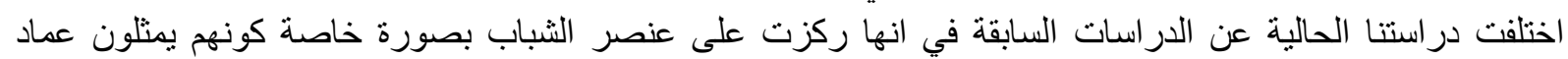

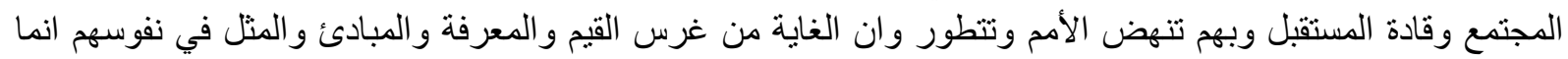

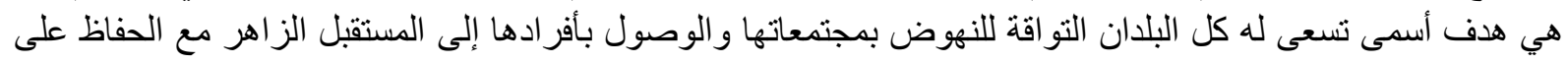

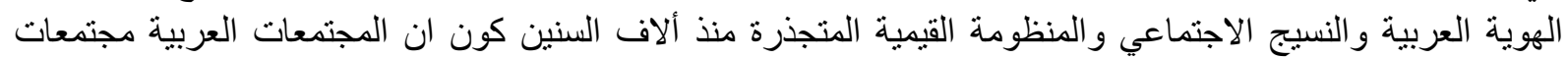
ذات أرث حضاري وتاريخي عريق.

المبحث الثالث

تمهيد..

يعاني الثباب اليوم من تغير في القيم والمعارف و المبادئ و العلاقات و التنظيمات و الأساليب و السياسات و التربية و التنشئة

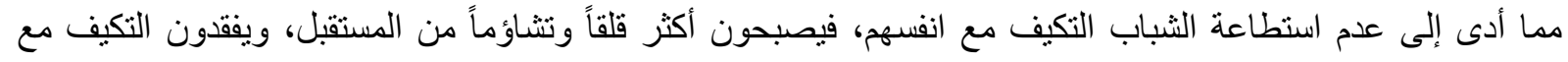

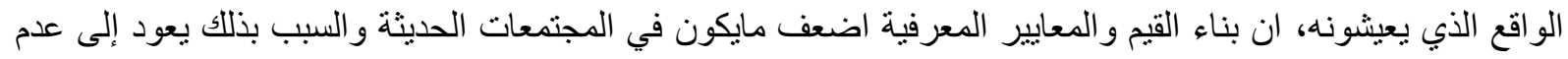

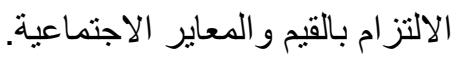

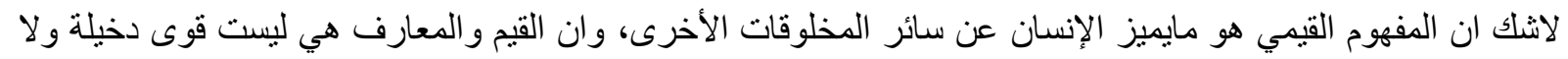

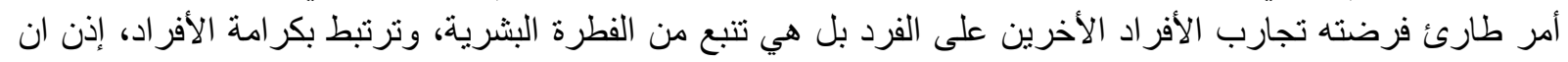

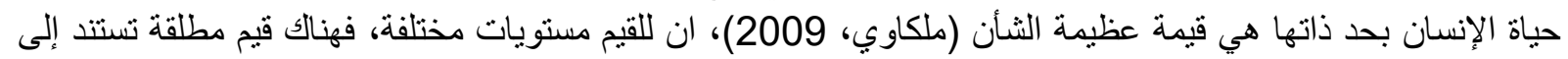
الفطرة الإنسانية داخل الأفراد جميعاً على اختلاف مستوياتهم، و هنالك منظومة القيم التي تحددها قيم المجتمع السائدة وهي 
تختلف من مكان إلى أخر باختلاف الأفراد والمجتمعات والمجالات الحياتية والمستوى النقافي والتعليمي، وهناك القيم المنفردة.

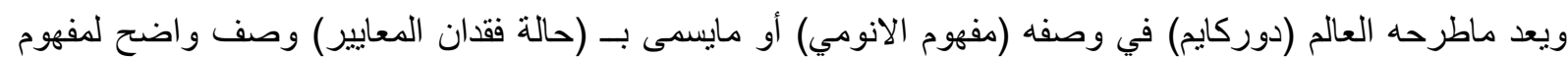

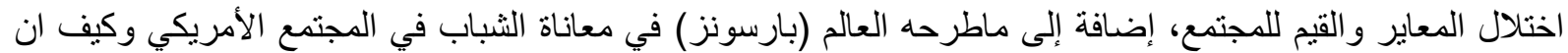

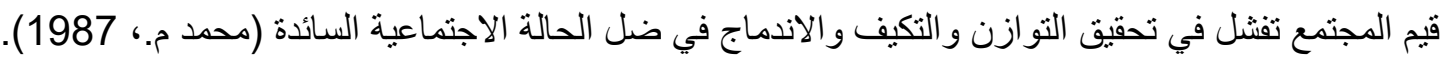

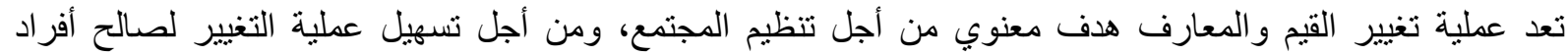

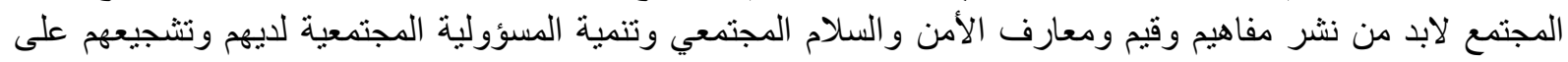

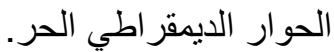
إن افر اط الثباب في استخدام مو اقع التو اصل الاجتماعي أدى إلى التفكلك الاسري إذ باتت الأسرة اليوم لاتجتمع على مائدة

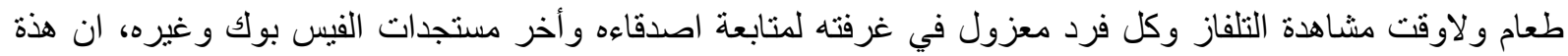

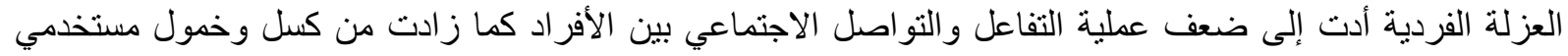

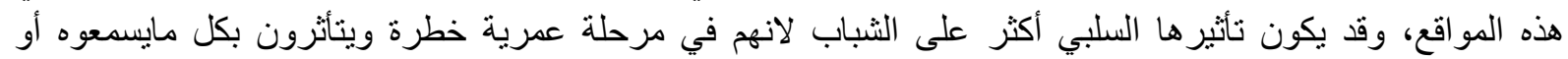

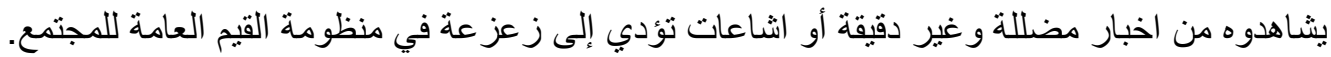

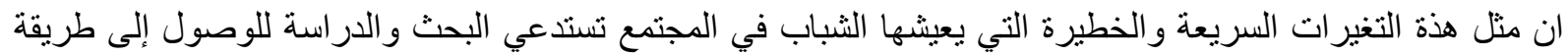
تفكير هذة الفئة و إلى أسلوب التعامل التعل معهم.

\section{الأسباب الرئيسية التي تؤدي إلى الاختلال القيمي والمعرفي لاى الثباب (العلي، 2006):-}

1ـ الانفتاح المفاجئ و الغير مسبوق على العالم الخارجي (العولمة) ما أدى إلى ضعف التمسك بالقيم و العادات و التقاليد و المبادئ السائدة في المجنمع.

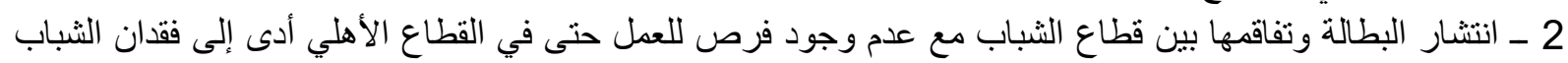

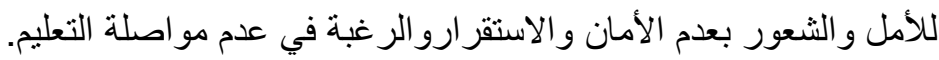

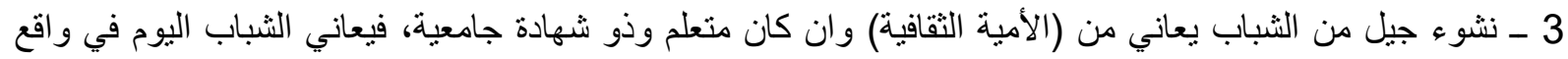

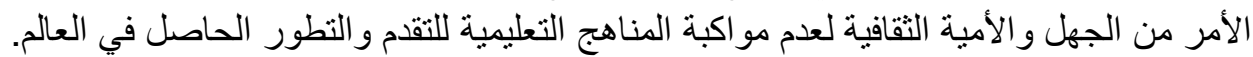

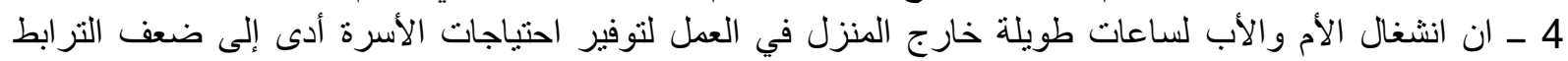

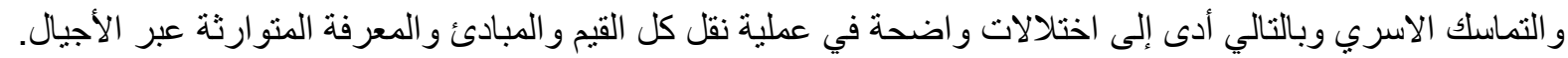

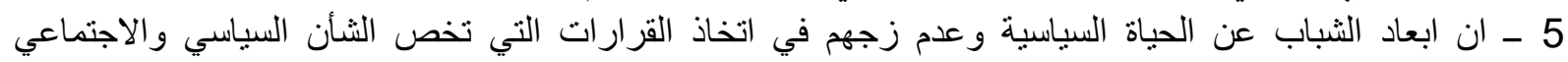

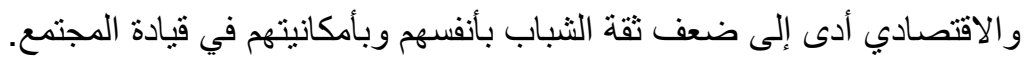

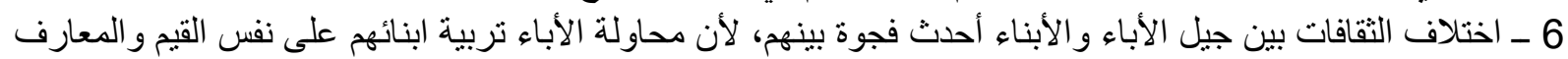

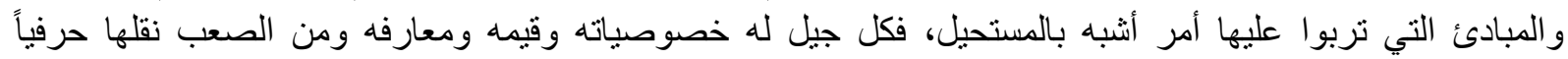

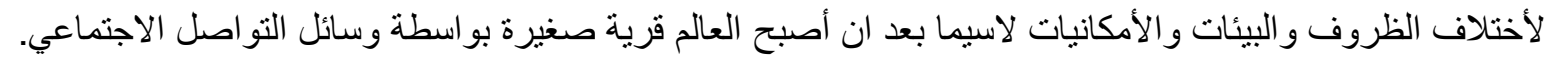

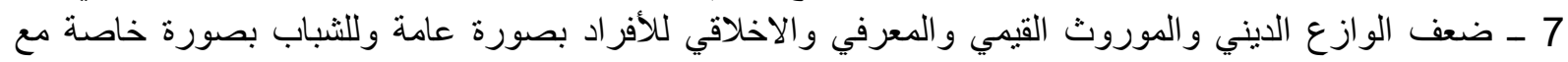
ضعف هيمنة السلطة الأبوية على أفراد الأسرة.

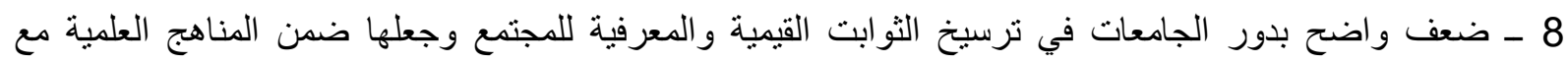

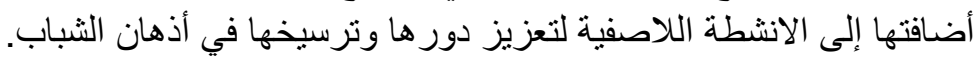

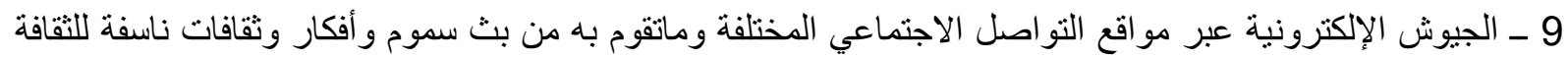

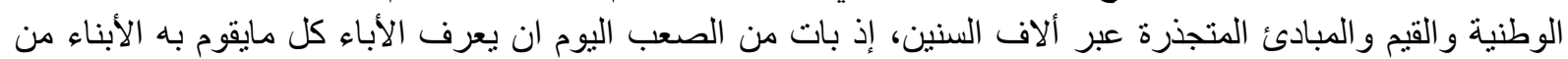

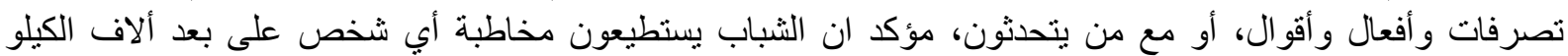
مترات من دون قيد أو شرط. ـ إن منظومة القيم و المبادئ والمعرفة في جميع المجتمعات تتعرض إن إلى تغيير مستمر ، نتيجة مايطر أ على المجتمع من

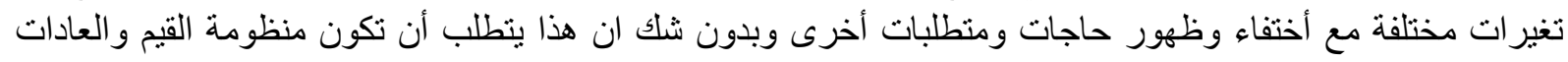

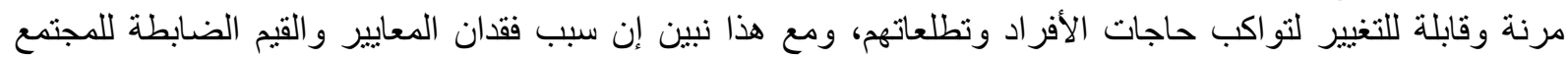

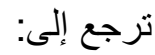




\section{EDUCATION AND ITS ROLE IN THE MORAL AND COGNITIVE CHANGE OF}

\section{YOUNG PEOPLE}

* التفكك الثخصي وتبني الأفراد مفاهيم الحرية المطلقة والتحرر مع انعدام الضوابط والأعراف التي تحددها القيم و و المبادئ المقبولة اجتماعياً.

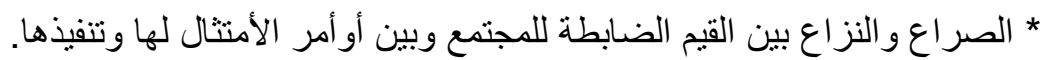
* التغيرات الثقافية والاجتماعية المفاجئة والمضادة لسلوك بعض الأفراد وتوقعات الأدوار التي يقومون بها (حسن،

* إن القيم التي يكتسبها الثباب اليوم لم تعد مرجعيتها إلى الأسرة، مما زاد من حالة عدم الاستقرار بين القيم المتوارثة عبر الأجيال وبين القيم المكتسبة.

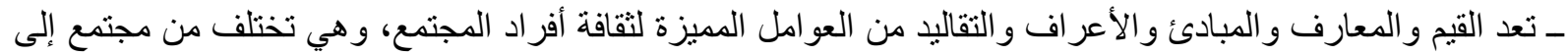

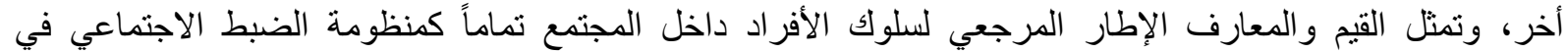

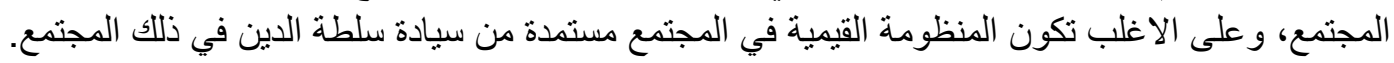

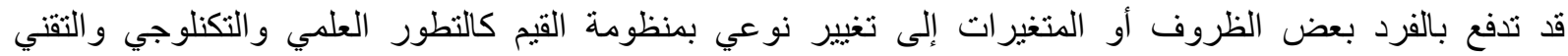

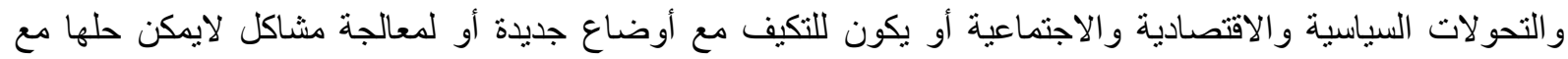
الموروثات القيمية و المعرفية القديمة.

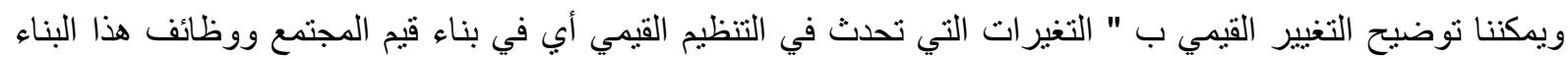

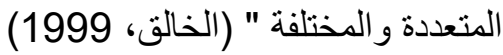
ويؤثر التغيير في منظومة القيم الاجنماعية على مجمل الأدوار والمهام للأفر اد في المجتمع، ادناه مخطط يوضح كيف يكون التغيير في القيم.

\section{* مخطط يوضح التغيير في القيم}

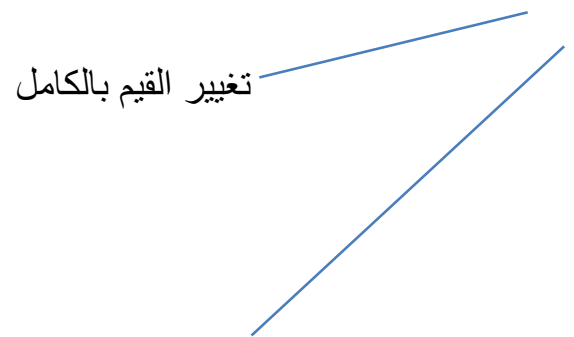

تغيير بعض من القيم مع اضافة قيم جديدة قد تكون مماثلة نو عاً ما للقيم السائدة

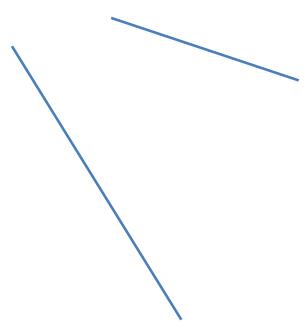

المحافظة على رصيد القيم نفسها من دون اي تغيير

تسعى المؤسسات التعليمية اليوم إلى تطوير منظومة التعليم وحثها على ان يكون هدفها الاسمى هو إعداد أجيال متفوقة في

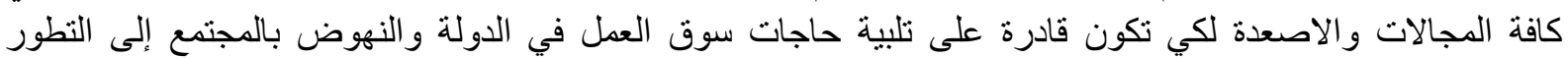

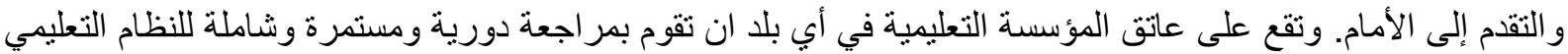

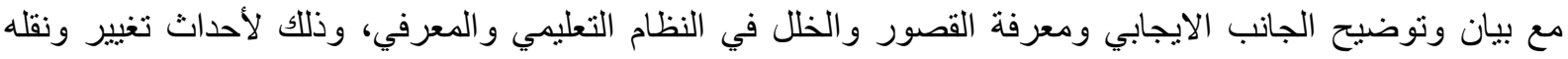
نوعية منميزة في تطوير وبناء شخصية الثباب من جميع جوانب ومجالات الحياة المعرفية والقيمية و المهارية و السلوكية لبناء جيل قادر على مواكبة التطورات والقزز ات العلمية الحاصلة في دول العالم ومن جانب أخر المحافظة على الهوية

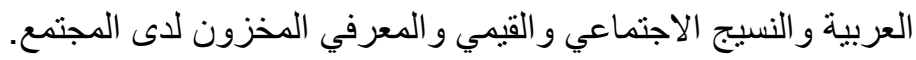




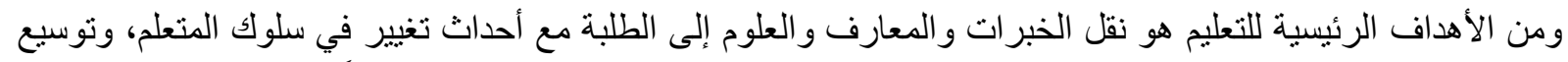

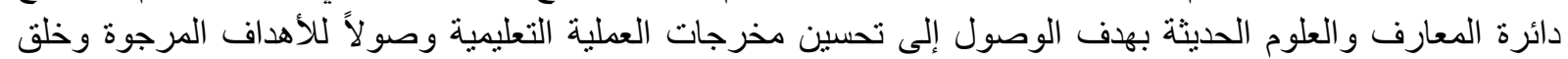

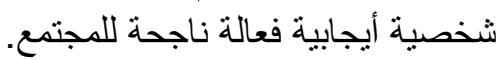

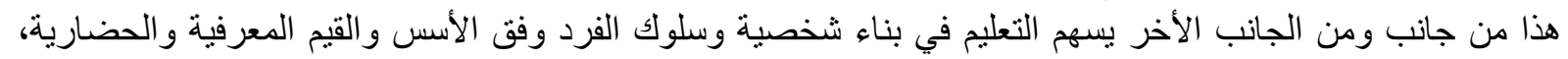

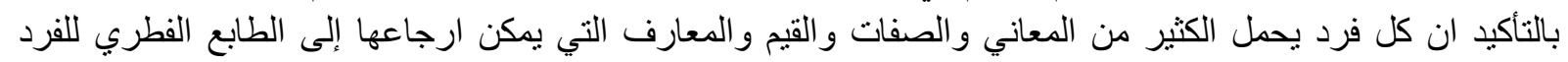

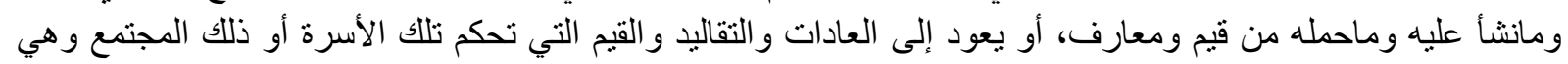
بالطبع قيم مكتسبة من البيئة المحيطة، ان جميع هذه العناصر الفطرية والمكتهبة المية تعمل بشكل تفاعلي لتبرز شخصية الفرد

(ابر اهيم، 2001)

ومن خلال الطرح السابق يتبين لنا ان الهدف الأسمى الذي يسعى له التعليم هو الاستثمار في الفرد (الاستثمار

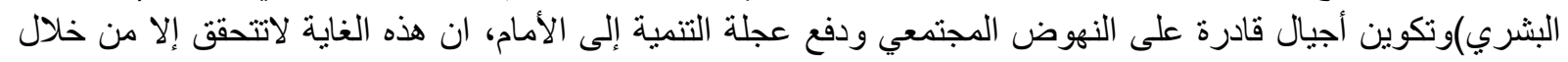

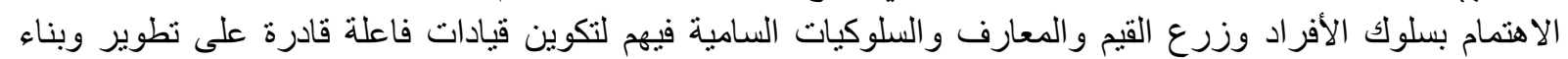
المجتمع. وبالتاكيد ان دور التعليم لايقل أهمية عن دور الأسرة في عملية غرس القيم و المعارف والمبادئ و اكساب الفرد السلوكيات

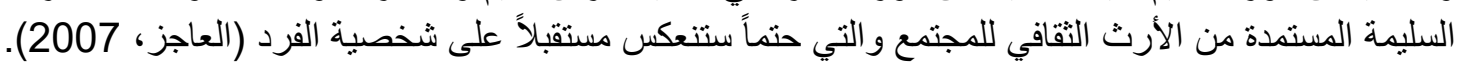

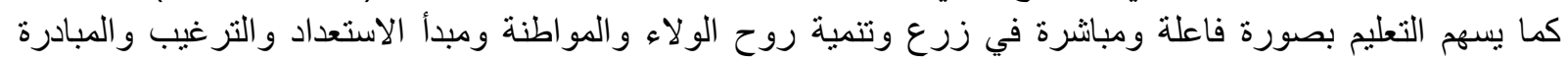

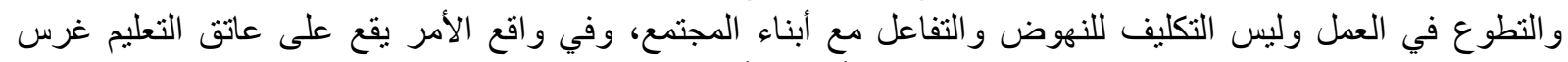

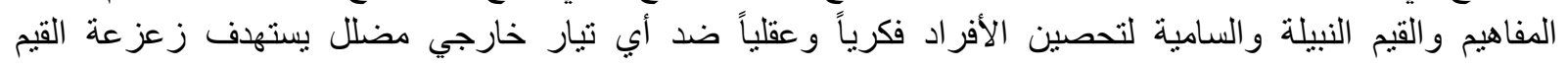

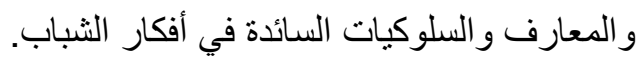

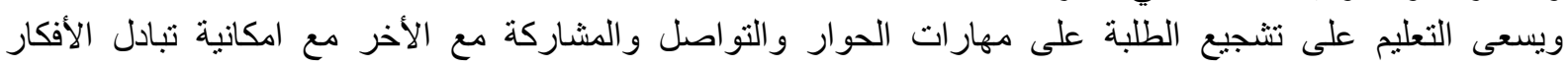

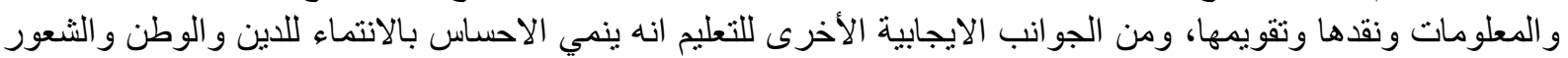

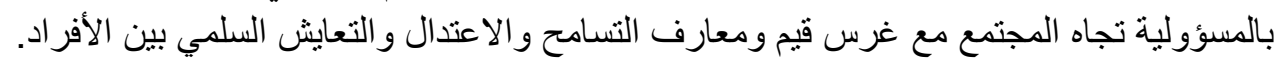

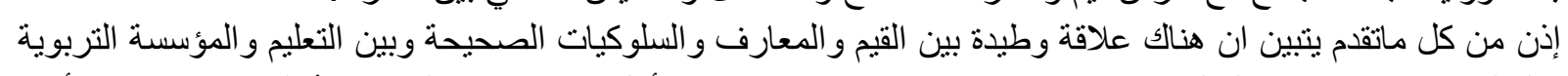

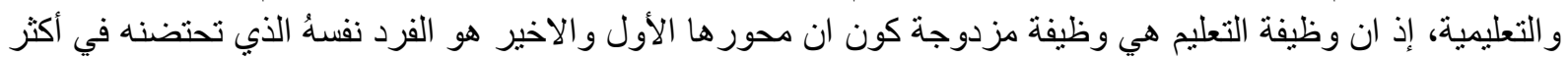
مر احل حياته أهمية.

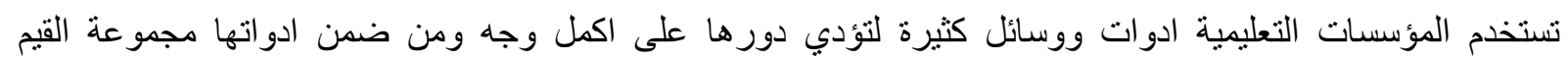

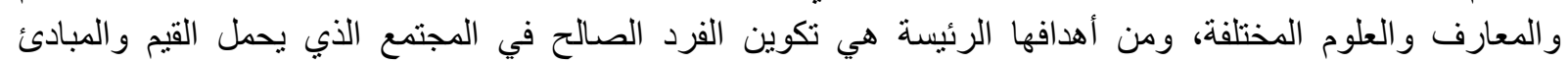

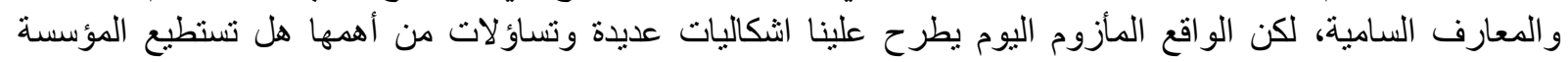

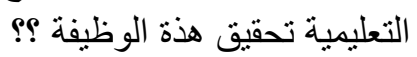

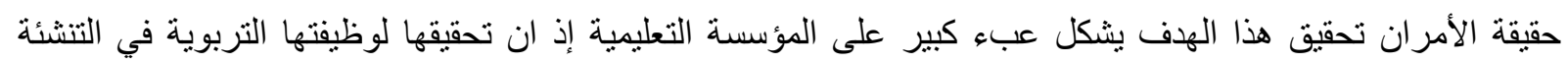

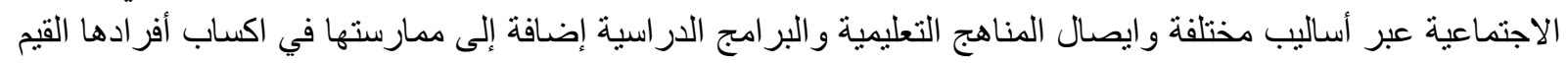

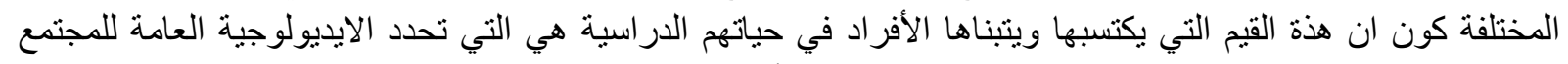

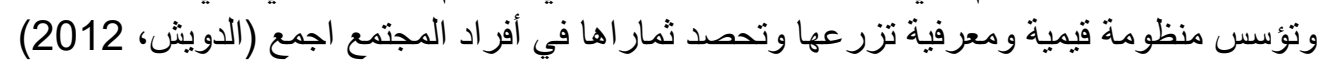

\section{التكنلوجيا الحديثة وتأثير ها على قيم وسلوك الثباب:}

تعد وسائل التواصل الاجتماعي اليوم من ابرز سمات التكنلوجيا الحديثة وهي ثورة جديدة في مجال حياة الأفراد فظهور

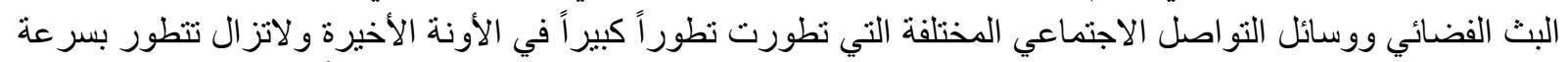

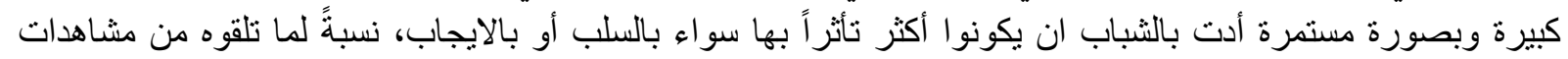

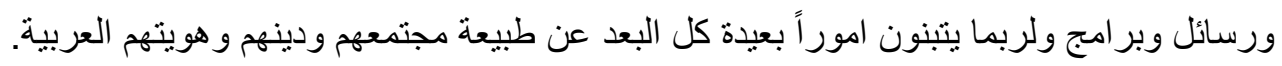

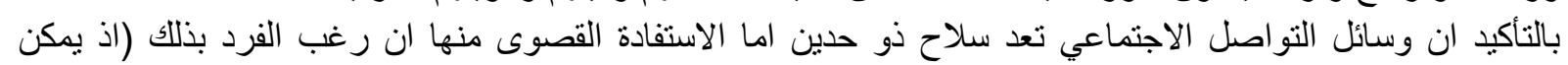

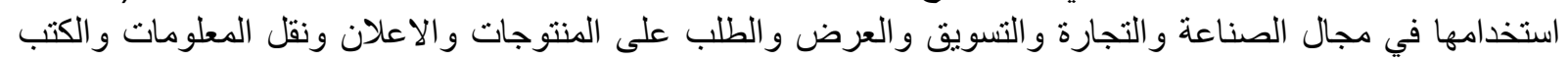

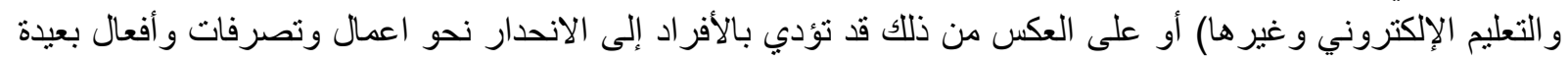

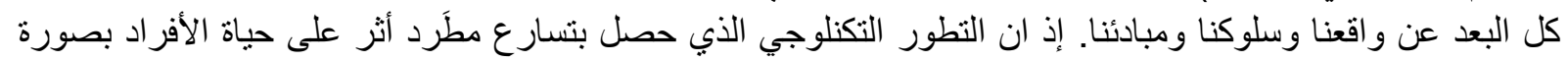

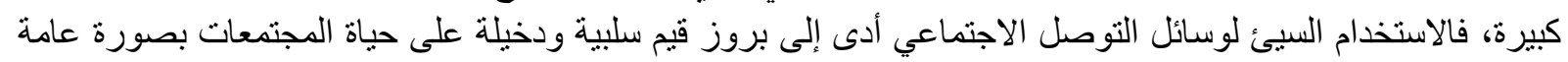


و المجتمعات العربية بصورة خاصة وكان من أبرزها هي اهتزاز منظومة القيم المعرفية إذ ان الضابط والمعيار الأساس

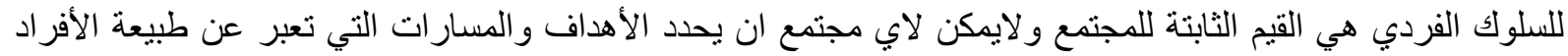

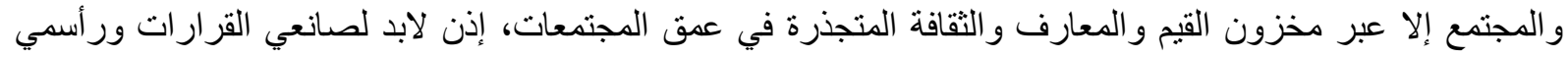

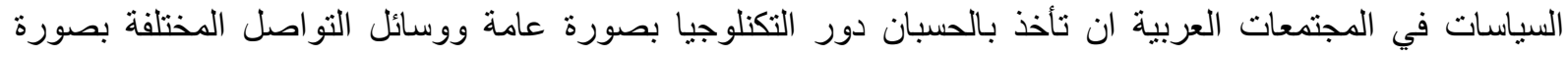

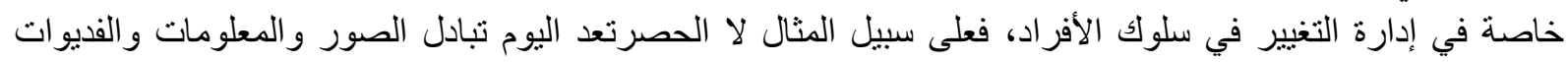

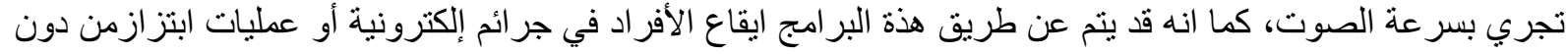

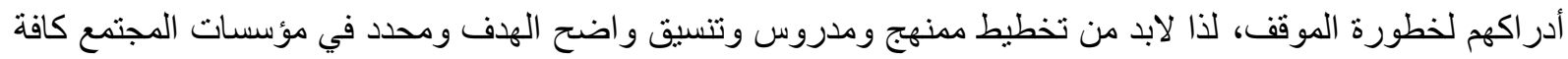

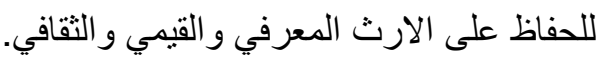

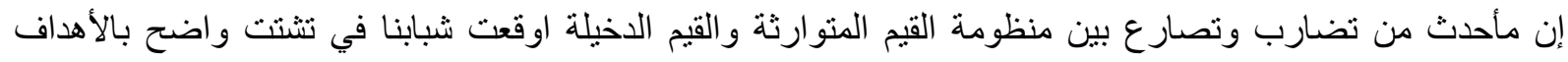

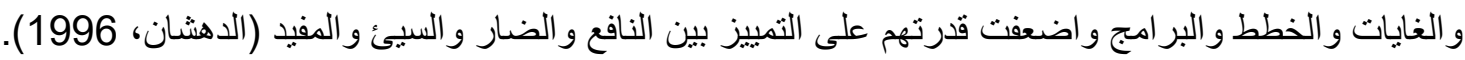

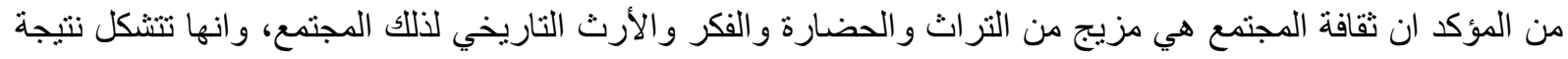

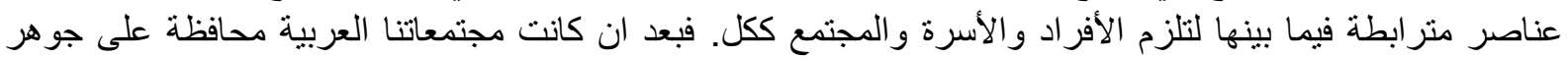
هويتها وتقاليدها و عاداتها لوقت قريب، حدث بعد ذللك خرق في منظومتها القيمية والمعرفية نتيجة الانفتاح الفكري

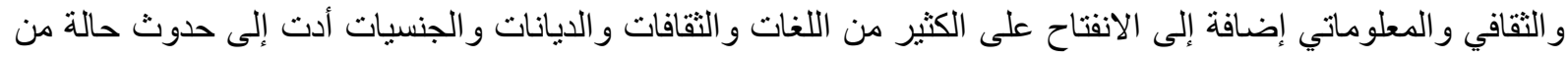

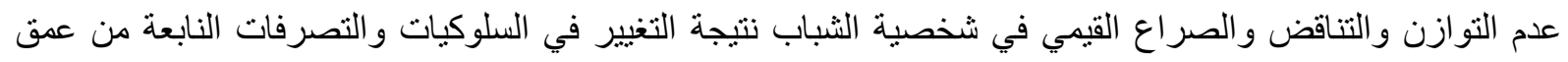

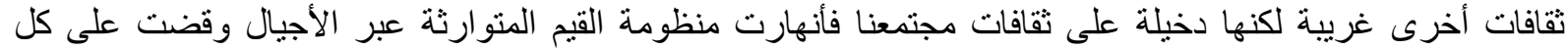

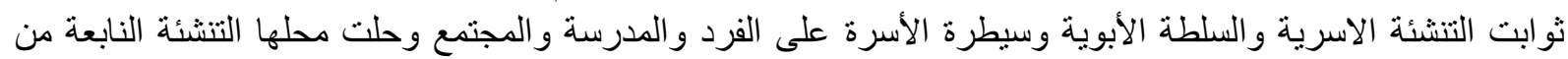

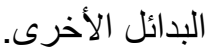

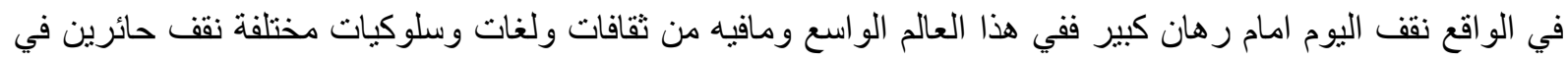

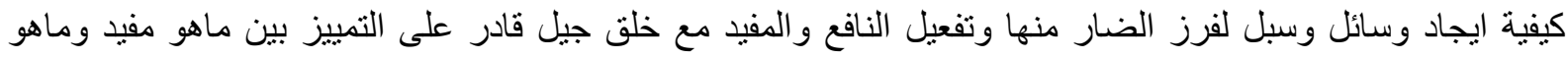

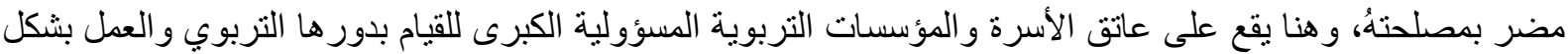

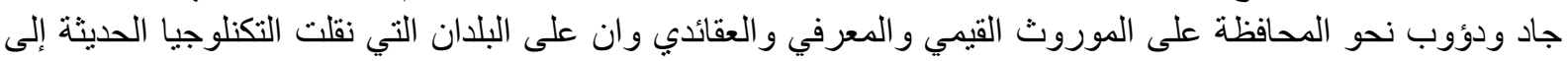

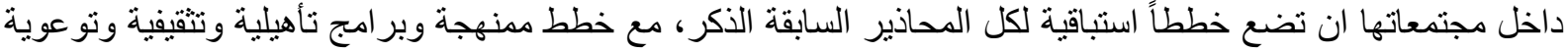

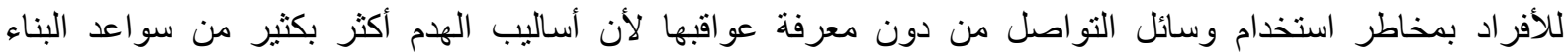

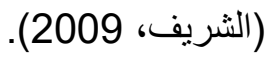

التوصيات والمقترحات:

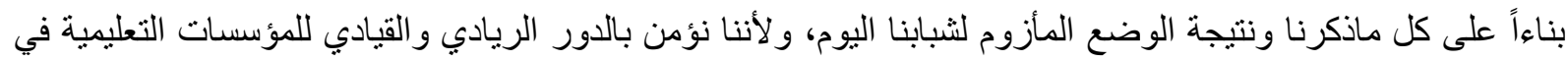

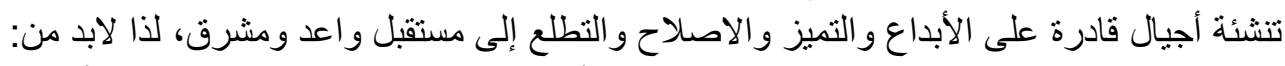

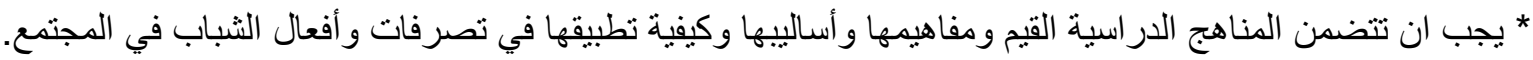

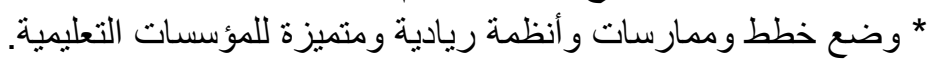

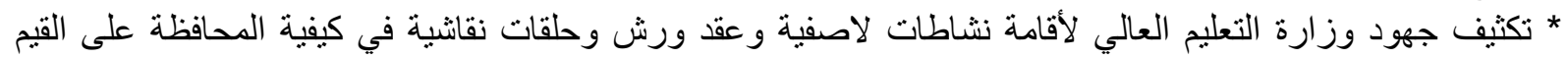

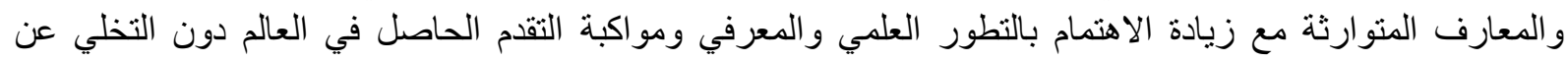

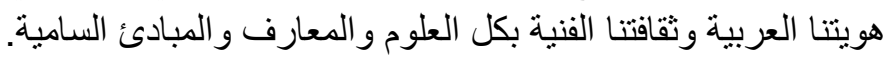

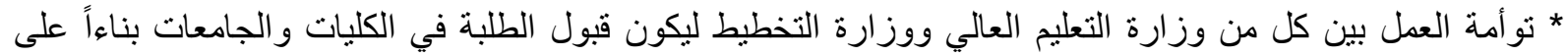

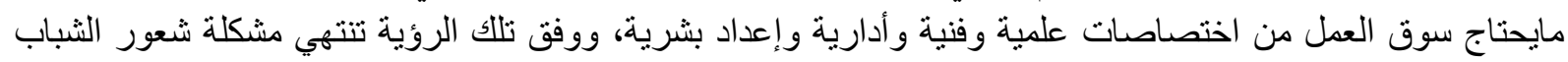
بعدم جدوى التعليم و عدم الاستفادة منه.

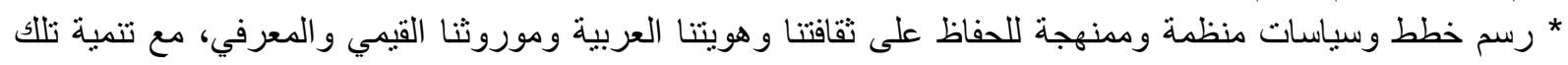

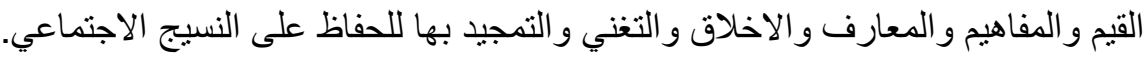

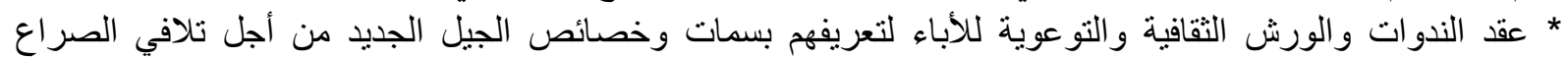

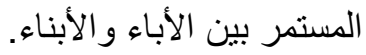
* الاهتمام بوسائل الاعلام بكل الصناء الصنافها (المرئية والمسموعة والمقروءة) لما لها من دور مهم وفعال في نشر القيم المعرفية وغرس الثقافة القيمية بين فئات المجتمع أجمع. 
* تقبل مبدأ الاختلاف في الأفكار والتعددية في الاراء ودفع الثباب إلى الانطلاق نحو العالمية وان يكونو ا قادرين على الإنى

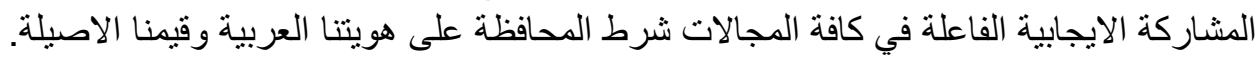

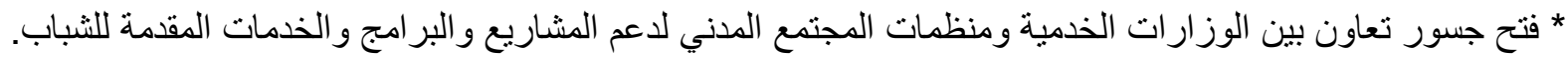

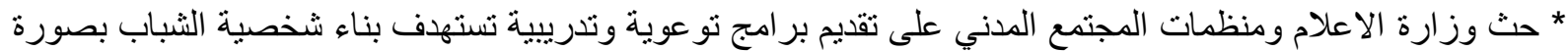

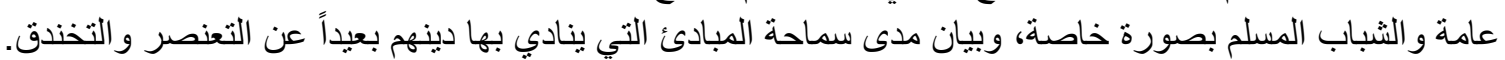

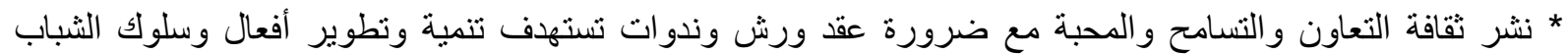

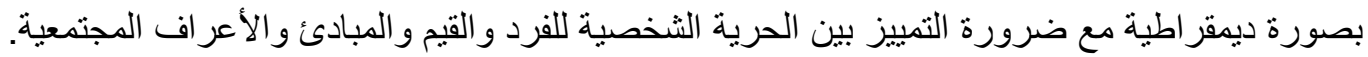

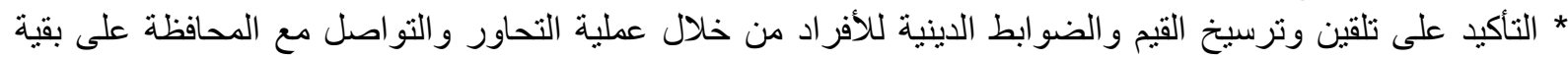
القيم السامية الأخرى كحب الوطن و الو لاء للهُوقيم التر ابط و التماسك الاجتماعي، علماً ان كل هذه القيم و المعايير و المبادئ

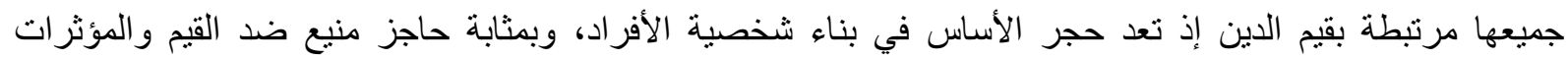
الخارجية الدخيلة على مجتمعنا. * حث و غرس قيم التنمية المستدامة في نفوس الثباب لحماية التئة البيئة و الحفاظ عليها للأجيال القادمة.

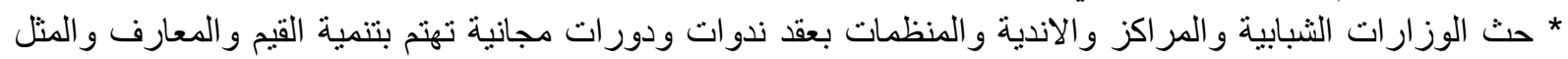

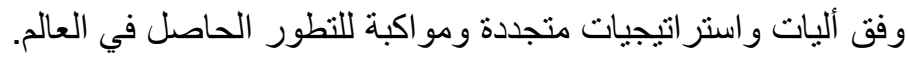

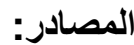

ابراهيم، يحيى عبد الحميد(2001): استراتيجيات النجاح واسرار التميز، مطبعة دار الطباعة للنشر الاسلامية، القاهرة، مصر.

احمد، مقبل احمد محمد، (2005): التعليم و علاقتهُ بسوق العمل، مجلة البحوث الاقتصادية العربية، مصر.

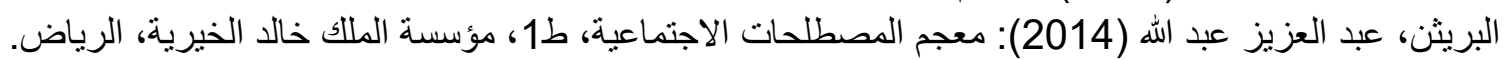
الثويني، محدد عبد العزيز، محمد، عبد الناصر راضي، (2012): دور المعلم الجامعي في تحقيق الأمن الفكري لطلابه الفيه في ضوء تداعيات العولمة، السعودية.

حسن، السيد الثحات احمد (1988): الصراع القيمي لدى الثباب ومواجهته من منظور التربية الاسلامية، دار الفكر العربي، القاهرة.

الدخيل، عبد العزيز عبد الله (2012): معجم مصطلحات الخدمة الاجتماعية، ط2، دار المناهج للنشر والتوزيع، المملكة الاردنية الهاشمية.

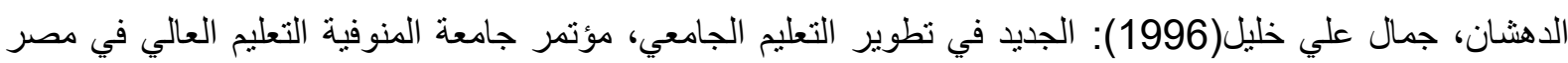
وتحديات القرن ال (21)، مركز إعداد القادة، الجهاز المركزي للتنظيم والادارة.

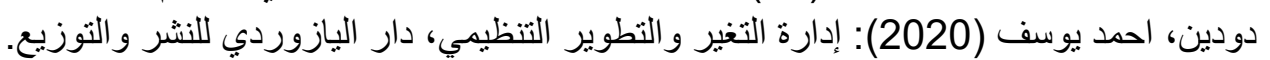

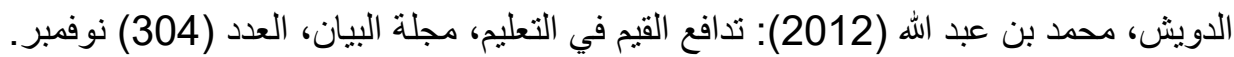

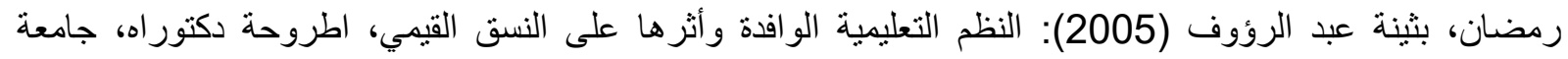
السلمي، احلام عنيق مغلي (2019): مفهوم القيم وأهميتها في العملية التربوية وتطبيقاتها السلوكية من منظور اسلامي،

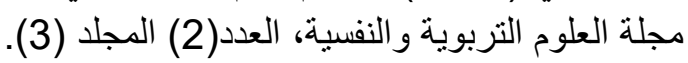

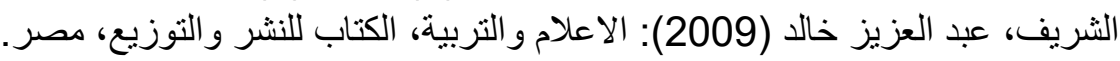

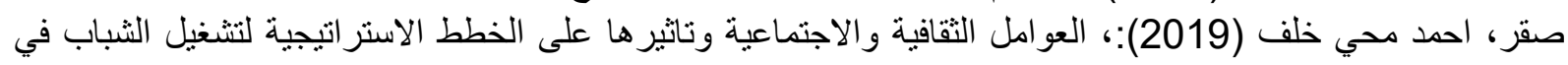
بعض دول العالم، دار التعليم الجامعي، الاسكندرية.

العاجز ، فؤاد علي (2007):دور الجامعة الاسلامية في تتمية بعض القيكية القيم من وجهة نظر طلبتها، مجلة الجامعة الاسلامية،

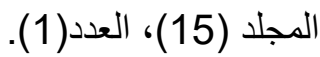

عبد الخالق، عبد الله (1999): العولمة جذورها وفروعها وكيفية التعامل معها، مجلة الفلك، مجلد(28) العدد(2)، الكويت. 


\section{EDUCATION AND ITS ROLE IN THE MORAL AND COGNITIVE CHANGE OF}

YOUNG PEOPLE

عبد الكافي، إسماعيل عبد الفتاح (2003): معجم مصطلحات عصر العولمة / مصطلحات سياسية و اقتصادية واجتماعية ونفسية و إعلامية.

عبد الكريم، هبة عبد المحسن(2021): دور منظمات حقوق الإنسان في تمكين المرأة العراقية، انشراقات تنموية، مجلة

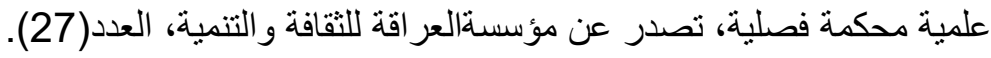

العلي، رجاء زهير (2006): التغير القيمي والمعرفي وتأثيره على شخصية الثباب الجامعي الفلسطيني، مجلة اتحاد

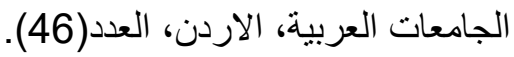

محاسنة، عمر موسى (2018): أساسيات التعليم المهني، المملكة الاردنية الإنية الهانشية.

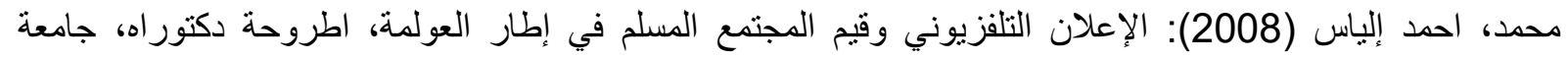
القراءن الكريم و العلوم الاسلامية، السودان.

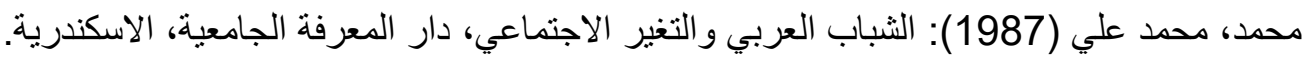

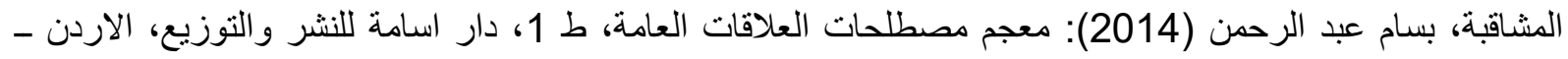

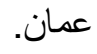

مصطفى، نادية محمود (2010) سيف الدين عبد الفتاح وأخرون، القيم في الظاهرة الاجتماعية، دار البشير للثقافة و العلوم، القاهرة.

ملكاوي، فتحي حسن (2009): القيم العالمية، مجلة الفكر الاسلامي المعاصر، مجلة فصلية محكمة يصدرها المعهد

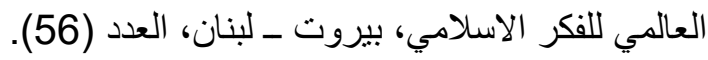

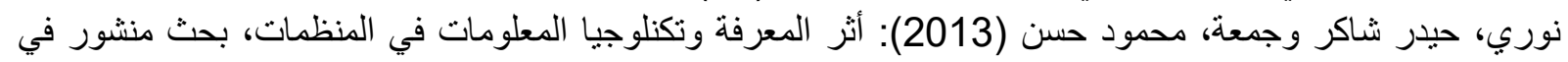

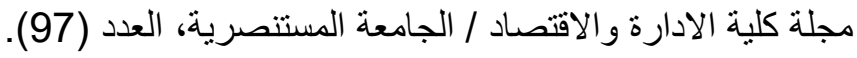

